\section{A MILK OUTBREAK OF SCARLET FEVER.*}

By D. S. Davies, M.D.Lond, D.P.H., Medical Officer of Heaith for Bristol.

THE number of deaths recorded from scarlet fever in Bristol was slightly less in 1891 than in 1890 , although the total number of cases was in excess, after making allowance for the first six weeks of 1890 before notification was in force.

This excess of cases notified is almost entirely accounted for by the milk epidemic which occurred in the first weeks of $189 \mathrm{r}$, giving rise to some $25^{\circ}$ cases, with, however, very small mortality.

This epidemic exhibited very markedly the general characteristics of outbreaks of disease transmitted by milk.

r. The outbreak was sudden, and the cessation well marked; a large proportion of the attacks were nearly simultaneous, and the outbreak reached its maximum very rapidly, as seen from the record of weekly notified attacks.

Week ending-

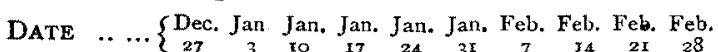
$\begin{array}{lllllllllll}\text { ArTACKS...... } & 6 & 12 & 22 & 104 & 3^{8} & 28 & 26 & 24 & 11 & 13\end{array}$

2. In several cases during this outbreak it happened that two or more persons in the same household were taken ill at the same time. Thus, two cases were notified simultaneously in each of twelve houses, three cases in each of two houses, four in each of four houses, and five cases in each of three houses; these particulars relate to the first invasion of each household.

3. A large proportion of the households attacked, viz., 70 out of 205 , or 34 per cent., had a common milk supply, and distributed by the same retailers.

4. In the districts most heavily affected, viz., St. Paul, St. James, and Ashley, one in 40 of the total inhabited houses in the district were attacked, whereas of the households supplied by the implicated retailers one in seven were attacked.

5. The disease affected chiefly consumers in the well-to-do classes. This was particularly noticeable in an offshoot of the epidemic in Clifton, where also the number of attacks amongst the adult population was greater than is found when the disease is spread by the usual school or visiting exposure to infection.

The case-rate was, as nearly as can be estimated, about 6 per cent., that for the whole city during the year being only 4 'I.

The sudden increase of notifications in the second week of January caused an immediate inquiry to be made, which served to connect the chief prevalence of the disease with two milk rounds in the city, and further inquiry showed the milk distributed in the infected districts to have been derived from two milk farms in an outside

* From Dr. Davies’ Annual Report for 189. district where scarlet fever had for some weeks been very rife. On Monday, January i 2 th, the retailers, who gave very ready and prompt assistance, stopped distributing all suspected milk in the city, and also discontinued supplies from the implicated farms. These farms were also visited with the view of discovering whether there was any disease amongst the animals of a scarlatinal nature, but no history of any such illness, nor any present indications of its presence could be discovered, and the manner in which the infection can have gained access to the milk has never been clearly demonstrated, though the prevalence of scarlet fever in the district would support the suggestion of possible contamination by some of the workers on the farms.

Notification proved of extreme service in calling early attention to the presence of an unusual amount of scarlet fever in the city, and in expe diting the taking of early precautions, without which the extension of the disease might have been considerably more serious. On subsequent occasions, also, notification has directed attention to an excess of the disease amongst the scholars at particular schools, usually through the continued attendance of an unrecognised case, and has permitted of early inquiry, followed by necessary precautions.

\section{THE ETIOLOGY OF CANCER OF THE SCROTUM.}

The lectures recently delivered by Mr. Henry $\mathrm{T}$. Butlin at the Royal College of Surgeons throw important light on the etiology of this interesting disease, and are of importance from a hygienic standpoint. The main conclusions of the lectures may be summarised as follows :-

In the first place, cancer of the scrotum in sweeps is almost unknown in the chief European countries and in the United States of America; while contrary to what is commonly supposed, there is no reason to think that it is becoming less common in this country than formerly. The expen ience of surgeons everywhere shows that the tissues of the scrotum are peculiarly indisposed to cancer unless they are prepared for its occurrence by the work of sweeping chimneys, or in some other special manner.

In the next place, there is positive evidence that soot is the irritating agent which produces the excess of cancer among sweeps. That this is so, is confirmed by the occurrence of cancer in exceptional instances in other parts of the body, when these have been subjected to the chronic irritation of soot. The skin of chimney sweeps becomes harsh and dry, and small warts are very common among them.

Why then do the chimney sweeps of other countries not suffer? The explanation is to be found in the fact that, with the exception of Belgium and some parts of Northern Germany, England is 